\title{
Spouses of persons with dementia: Attachment, loss and coping
}

\author{
Reidun Ingebretsen and Per Erik Solem \\ NOVA: Norwegian Social Research, Munthesgt. 29, N-0260 Oslo \\ Reidun Ingebretsen: Telephone +4722541243 E-mail rin@isaf.no Telefax +4722541201 \\ Per Erik Solem: Telephone +4722541267 E-mail pes@isaf.no Telefax +4722541201
}

\begin{abstract}
The purpose is to study how spouses of persons with dementia cope with losses and caregiving tasks during the dementia process and how their coping is related to the individual's and the couple's history of attachment. The sample consists of 28 couples where one of the spouses has dementia. The caregiving spouses, aged 60-87, are interviewed at an early stage of dementia and are followed up every 6-9 months over a periode of three years. The life situation is continually changing, and coping methods are repeatedly challenged. Coping with losses and readjustments are dependent upon their need of the partner to feel safe. Different patterns of attachment behaviour are seen. Compulsive caregiving spouses attend to their spouse beyond their needs. Spouses in anxious attachment often panic and try to fight back the symptoms of dementia. A pattern of compulsive self-sufficiency manifests itself as arguing or withdrawal from the partner. Secure attachment makes it easier to accept the changes, keep in contact and care. To understand the strains and coping of the spouses, we need to understand how dementia triggers patterns of attachment behaviour. They need more than information on dementia and training in handling various symptoms. They need empathy and individually adapted interventions.
\end{abstract}

\section{INTRODUCTION}

Emerging dementia with gradual mental deterioriation and increasing dependency ending in death, is frightening to those involved, both to the person himself and to the family. The new situation disturbes an established balance in the relationship and interferes with communication. Meaningful mutual contact and shared meaning is gradually lost.

In the book 'Living in the Labyrinth' Diana Friel McGowin, who had received a diagnosis of dementia, writes: 'My every molecule seems to scream out that I do, indeed, exist, and that existence must be valued by someone! Without someone to walk this labyrinth by my side, without the touch of a fellow traveller who understands my need of self-worth, how can I endure the rest of this uncharted journey?' (Cited after Kitwood 1997, p. 15). This person is in desperate need of a secure attachment figure to recognize, help and guide her. In this paper we are focusing on the situation of the fellow traveller, the chart reader; the spouse.

The burdens of family caregiving for persons with dementia are documented in a great number of studies (Morris \& Morris 1993). The tasks of a fellow traveller and navigator in the labyrinth of dementia are, not least due to strong personal involvement, also hard to endure. Research does not reveal any clear and simple conclusions on how coping stategies, social support or professional interventions may ease the burden (Zarit et al. 1986). By including attachment theory in the framework of analysis, we hope to come closer to understanding changing relationships and how burdens may be eased.

From an outside position it is difficult to ascertain what the most heavy burdens are. A distinction has to be made between objective and subjective burden (Duijnstee 1992, Morris \& Morris 1993). The objective burden, often measured by severity of dementia symptoms, is not strongly associated with subjective burden as experienced by the caregiver (George \& Gwyther 1986, Zarit et al. 1986). 'Over time the meaning given to a stressor seems more important than its occurence' (Lévesque et al. 1998, p. 253). When the goal of the efforts not only is to give good care, but also to maintain a relationship, burden may have to be measured by different standards. Objective burden, or elements of objective burden, may even be evaluated in positive terms by the caregiver (Farran et al. 1991, Grafström 1994, Motenko 1989). Caregivers may need elements of 'the burden' in order to maintain attachment bonds or to fulfill their obligations. Interventions to take such burdens away, without considering the underlying needs or goals, may interfere with the best interests of the caregiver - and of the person with dementia.

This article is based upon a study with the purpose of finding out 1) how spouses of persons with dementia cope with the losses they experience and the caregiving tasks they perform during the dementia process, 2) how their coping methods are related to the individuals' and the couple's history of attachment, and 3) which consequences different coping methods and attachment behaviour have for intervention. 
We will present the theoretical considerations and conceptual work of the study, and discuss results by illustrative selected cases.

\section{THEORETICAL FRAMEWORK}

Attachment theory introduced by Bowlby $(1969,1973$, 1980), is widely used in studies of mother-child relations, and is increasingly extended to other periods of the life span (Antonucci 1976, Sperling \& Berman 1994), even to old age (Cicirelli 1991) and dementia (Miesen 1992). Attachment behaviour is defined as all behaviour which has the goal of obtaining and/or maintaining a desired proximity of another person (Bowlby 1969). Attachment behaviour is released when safety needs are threatened. Attachment is a security-based bond providing protection, comfort and help (Cicirelli 1991). Antonucci (1994) finds that people in their inner circle of attachments seek support in terms of confiding, respect, reassurance, care, talking about their health and talking about their worries.

Attachment is classified in two main categories: secure and insecure. Secure attachment is seen when the person is able to tolerate separation from the attachment figure (Antonucci 1994). In terms of the concept 'internal working model', which is often used in the attachment litterature, in secure attachment this mental representation reassures the person that the attachment figure will return and/or that the person is able to cope with the separation. Thus the internal working model includes information both on the attachment figure, the self and the relationship. As argued by Antonucci (1994), secure attachments may foster a feeling of personal efficacy or confidence in own ability to cope.

In general, attachment refers to an individual trait or disposition, it is the person who has secure or insecure attachment to an attachment figure. However, it is also part of a relationship, and in older couples the reciprocity of attachment is obvious. A person with dementia needs help, comfort and security from the spouse, but even the spouse may have needs for security that the other is unable to fulfill. Bretherton (1991) sees an emotionally open communication between the partners as a part of secure relationships. This may be difficult when mental deterioriation emerges, but emotional signals may be coded correctly even if cognitive abilities are weak, and emotional messages behind confused verbal communication or non-verbal communication may be grasped by empathic understanding.

Insecure attachment is classified in different patterns. Insecure or anxious responses of infants to the standardised 'Strange Situation' is classified as avoidant or ambivalent (Ainsworth at al. 1978). A disorganized/disoriented pattern is observed among abused or neglected infants (Main \& Solomon 1986). Bowlby (1980) has observed three different patterns in adults prone to pathological mourning; anxious attachment suffused with ambivalence, compulsive care-giving, and strenous attempts to claim emotional self-sufficiency and independence. We have found these patterns in an earlier study on spouses of persons with dementia attending support groups (Ingebretsen \& Solem 1997). Mayseless (1996) argues that the three adult patterns described by Bowlby are consistent with the childhood patterns of ambivalent (anxious attachment), avoidant (self-sufficiency) and the disorganized/controlling behaviour (compulsive caregiving). Main et al. (1985) use the terms 'dismissing of attachment' and 'preoccupied with attachment' to describe insecure patterns among adults. Crittenden (1997) has extended this with a number of subpatterns in four groups; dismissing, integrated, preoccupied and anti-integrated. Her Dynamic-Maturational Model of Attachment is a lifespan model of the development of strategies for coping with dangerous situations. According to the model, there is both stability and change of such strategies over the life-span. The model is also described as a model of the organization of relationships.

Thus, there are different conceptualisations of insecure attachment patterns. In this paper we shall try to outline the relational aspects of different insecure attachment patterns. There seems to be a common dimension in different patterns; regulation of the balance between proximity and distance. The dimension of proximity vs. distance is important in relationships in general, and it is challenged by the dependency of one of the partners. There seems to be no easy way to find a balance between separation and distance on the one hand, and proximity and the continuation of a 'we'relation, on the other. When one of the spouses has dementia, there is a gradual loss, and completing grief work to the extent of finishing the relationship may be impossible. Letting go, or what is described as a separation-individuation conflict (Gwyther 1990, Rose \& DelMaestro 1990) is hard to resolve when the mutuality of the relationship is fading away at the same time as the dementing spouse is increasingly dependent upon the caregiver's attention. There is a risk of rushing to extreme reactions like either clinging to (preoccupying with) or avoiding (dismissing) the attachment relationship. We may get some help to understand this risk by considering more carefully the history of the relationship, and the attachment behaviour of both partners.

Another dimension underlying different patterns of reactions is the flexibility of the internal working model, whether it is open to change when the capacities of the dementing spouse and the relationship are changing, or if the model tends to freeze. A frozen internal working model of attachment would dispose for compulsive/obsessive reactions.

Lack of open communication between the spouses may restrict the flow of information through the internal working model (Bretherton 1991), and thus interfere with revision of the model. In dementia, communication is difficult, which may increase the probability of the model to freeze. 
Loss is a main challenge spousal caregivers are exposed to. Loss of a secure attachment figure or a mutual potentially comforting relationship is one such loss. Whatever the strength of attachment needs in the relationship, dementia represents a loss of the person as he used to be. Thus mourning is part of the picture for spousal caregivers. For some the loss of a responsible problem solver is most prominent, others may be more disturbed by loosing a discussion partner or a sexual partner. Lost freedom caused by caregiving on a 24 hours basis is also frequently mentioned by spousal caregivers. The content of losses may differ, but feelings of loss seems to be a common denominator for family caregivers (Nordhus 1994). Their coping abilities and strategies are challenged.

Coping is classified by Lazarus \& Folkman (1984) as: 1) active management of the situation (problemfocused coping) and 2) emotion regulation (emotionfocused coping). Action directed at altering the stressful situation is problem-focused, while coping directed at regulating negative emotions resulting from the situation is referred to as emotion-focused. Denial and wishful thinking are examples of emotion-focused coping, directed at altering the appraisal of the situation rather than the situation itself. When the situation is complex and continuously changing, as in the process of dementia, there is a need for varied and flexible coping strategies. The more uncontrollable the situation is, the more adaptive is emotion-focused coping (Lazarus 1998).

According to DeLongis and O'Brien (1990) successful coping not only depends on our ability to solve problems or to regulate emotions, but also on regulation of relationships with involved others. They introduce a third category of coping: relationship-focused coping, which is of special relevance to coping with a changing marital relationship. Relationship-focused coping is directed at regulating and maintaining social relationships of importance to coping with the stressful situation. This includes both relationships as sources of external support and relationships that are part of the stressful situation. Negotiating and compromising with involved others, and being empathic, are examples of relationship-focused coping. Empathic coping seems to be a special challenge to spouses of persons with dementia, as the persons' behaviour often is very difficult to understand. Empathy is characterized by on the one hand identification with the other in order to understand the situation in the way the other does, and on the other hand to recognize one's own separateness from the other, that is not to merge with the other.

In other words empathy implies a dynamic balance between proximity and distance, which is a central dimension of attachment. Berman et al. (1994) put it this way: 'The set goal of adult attachment is regulation of an optimal level of continued and stable proximitydistance with an intimate... The regulation of proximity, in turn, regulates anxiety-security.' (p. 214). The optimal level of proximity is part of a contract between the partners. When brought out of the negotiated balance by the importunate behaviours or unavailability of the dementing spouse, primary emotions like anxiety or anger are likely to be activated.

Secure attachment is expected to go hand in hand with an optimal balance between proximity and distance, and thereby supporting successful coping by flexible ways of restoring a balance in accordance with the capacities of the person with dementia. In insecure attachment there is a greater risk of extreme reactions like avoidance (self-sufficiency or dismissing of the relationship) or clinging (anxious attachment or preoccupation with the relationship) which is likely to be incompatible with empathy. When the internal working model of attachment is frozen, reactions tend to be compulsive. It is difficult to take alternative perspectives, to negotiate and compromise, and to make flexible use of various coping strategies.

\section{SAMPLE AND METHODS}

The sample for the study was recruited from the Memory Clinic at the City Hospital of Oslo, where people with memory problems come for diagnostic examination. Spouses of persons with diagnosed dementia in an early stage, were by the staff of the Memory Clinic given an information letter about the project and were asked to volunteer for participation. Recruitment was closed when 32 couples had enrolled. Four of the caregiving spouses were reluctant to agree upon an interview. Thus the sample consists of 28 couples.

The caregiving spouses, aged 60-87, were interviewed shortly after enrolling and were followed up every 6-9 month over a period of three years (19961998). The semistructured, qualitiative interviews were audiotaped and transcribed. Each interview usually took 2-3 hours. The interview covers the following main topics; the present mental status and behavioural problems of the person with dementia, the burdens of caregiving, the health status of the caregiver, social network, use of public care services, coping strategies, the attachment and proximity/distance between the spouses, and the history of the marriage. The qualitative approach and a necessary sensitivity to the actual situation and needs of the caregiver, implies that the topics and sequenses are individualized. In addition to the formal interviews, in most cases we also had telephone dialogues in between. When feasible, communication within the couple was observed and taped.

\section{RESULTS}

Our longitudinal approach clearly shows that the situation of the caregivers is continually changing. Coping strategies are repeatedly challenged. The dependency of the person with dementia is increasing. During a period of two years, about half of them have moved to a nursing home, most often after a period in day care and/or respite care. Some of the partners with dementia 
have died during the study. These situations call for reappraisals, regulations of the expectations, ability to stand by, and ability to let go.

In this article, our main focus is on the regulation of the expectations to the person with dementia and of the proximity-distance in the relationship over time. In this respect different attachment patterns of the caregivers represent somewhat different challenges regarding the regulation of the relationship. To what extent dementia represent a breach of the established contract as regards the roles and the proximity-distance in the relationship will, however, also depend upon the behaviour of the person with dementia and the interaction between the spouses.

The caregiver's expectations of the dementing spouse are derived from the earlier basic contract of the relationship. The following are examples of expectations based on insecure attachment:

1. Be available for me (Don't be helpless, be my safety assurance).

2. I am not available for you (Don't come too close, don't disturb my independence).

3. I am available for you (Don't drift away from me we belong together).

These expectations are associated with three patterns of attachment behaviour when dementia emerges; anxious attachment, self-sufficiency, and compulsive caregiving, respectively.

\section{Be available for me (Don't be helpless, be my safety assurance)}

Dependent spouses have a strong claim on their partners to be available and reliable. More or less explicit the contract is based on terms like: Don't be helpless, be my safety assurance. It goes without saying that it is difficult for a person with dementia to live up to such expectations. In spite of defenses to realize and/or strenuous efforts to fight back the symptoms, spouses who need their partners as pillars to lean on to, will probably panic. When people are highly distressed or anxious they are unlikely to engage in empathic coping (DeLongis and O'Brien 1991).

A wife who paniced when her husband started to forget, tells that she cried out angrily: 'You can't take care of anything (me) anymore. Why do you do this to $m e$ ?' It is easy to understand such a reaction on the background of her own grief and insecurity, but her husband reacted with sadness and withdrawal from this threat to his vulnerable self respect. In another example, the vicious circle of nagging, anger and withdrawal stopped when the dementing spouse reacted positively to his wife's search for physical reassurance. This gave her some comfort and they managed to keep an emotional contact, which seemed crucial to both of them (Solem \& Ingebretsen 1997).

Keeping in mind that these spouses are looking for a safety assurance, this helps us to understand their efforts to reorient and 'wake up' their dementing spou- ses. A confused safety guard is a paradox. The world seems turned around, when these spouses have to search for their partners who literally are unable to find their way home. Instead of representing safety they picture a strange, unknown and unpredictable world. The confusion and insecurity of the person with dementia may function as a red cloth for some of these spouses and reinforce their own anxiety, anger and helplessness.

However, some reach a turning point, 'now, I am the strongest one', and they cope better than anyone could imagine beforehand.

Mrs. J had for many years before the dementia of the spouse been troubled with anxiety problems. She had relied on her husband to do shopping, to drive her to doctors and be around. Her dependency on her husband was obvious. She is proud to tell how she, after the initial period of anxiety and anger, managed to help and comfort her husband when he needed her. She understood that she needed to be the strong one, and she was. She more or less put her own anxiety aside as long as the man lived. 'It is not possible to have two helpless persons in the same couple'. She formed up to meet his needs as he had done for her. She was tired and some times quite depressed, and she had some emotional outbursts, but she did not panic and she did not give in. It was meaningful for her to try to pay back some of the care her husband had given her. By taking the strong position, the relationship was maintained, the balance reestablished and they followed a well-known model of relating to each other, although the roles were changed. It was helpful and comforting for her to interpret some of his 'strange' behaviour as a signal of his caring for her after all, i.e. when he came home with five big bunches of flowers instead of milk.

\section{I am not available for you (Don't come too close, don't disturb my independence)}

If a relationship depends on a carefully regulated distance and a predictable pattern of life, all changes in the person with dementia and the relationship, the very difference from how things used to be, may be threatening, due to the need of structure and control. Behaviour categorized as disruptions and intrusions are easily experienced as provocations to the spouse. Reprehensions and nagging may represent the efforts of the caregiving spouse to get the partner back to normal, even when knowing intellectually that it does not help. When the person with dementia gets emotionally upset, clinging, or fighting, the limits of the spouse are further challenged and an urge to push away or withdraw is sometimes rather obvious.

Mr. H told in detail about the interaction between the spouses and clearly illustrated that neither of them were comfortable with the changed pattern in the relationship. As bad luck would have it, Mr. H himself had a severe accident shortly after his wife got the diagnosis of dementia. He had a long hospital stay and rehabilitation period. His wife had to be taken care of 
by others in the meantime. When he returned home, her functioning was markedly reduced. 'I could hardly walk myself, and she could not even boil potatoes'. In addition to his own training, he had to give instructions about or take over most of the household tasks, which used to be her domain. Due to his own disabilities, her reduction was even more threatening to him. He felt locked up. 'I could not even run away'. They were trapped together, quite different from earlier days where both had their own friends and interests in addition to working roles. In contrast to what he described as a rather easy-going relationship, they now had a lot of nagging and quarrels. He told about his relation to the wife: 'I am the one who has to tell her what to do, and she protests a lot. I have to remind her about personal hygiene, and every step in ordinary activities. She is on guard, takes everything I say as criticism'. He tried to remind himself that her reactions are due to her illness. 'But when she, after I have done all the housework, including the cooking, tells me that I am a bad man because I don't wash the dishes at once, then it is sometimes really hard, not to push back'. To some extent he could see that she was vulnerable and defended herself. On the other hand he was rather irritated: 'I cannot go out-of-doors or to the toilet on my own, and all the time I have to help her in searching for her purse. Sometimes I tell her that she has nothing of value there, so it does not matter where this silly purse is. Then she gets very upset, and I have to search even more to calm her'. She could not remember and she could not even search any longer. She defended herself against this feeling of helplessness and dependency by telling her husband that she would be much better off without him. At the same time he had to take more care of her.

In this case the usual balance of proximity-distance in the relation was clearly disturbed. They used to spend a lot of time with their own interests, before they were more or less trapped by the dependencies of their own and the partner's. 'When you used to having your own head and your own feet, it is difficult to split it up and let the one partner represent the head and the other the feet.' When they came too close to each other, they seemed to do their best to push away the other, maybe even in order to fight back their dependency.

Mr. $\mathrm{H}$ told frankly that after his illness, his main concern was to take care of himself and focus on his own training program. In this process he was not very sensitive to his wife, and his main focus was not to maintain the relationship to her. In a way they both were 'deceived' at a time were they needed the partner most. Their way of telling themselves and each other that they can manage very well on their own is by minimizing the importance of the other. When she told him she would be better off without him, it was contrary to all evidence, and he could laugh at it. It still hurt however, and did not make it easier for him to be sensitive and empathic to her needs. The self-respect of both the partners were threatened, nourishing vicious communication circles.
In this case both partners were extra vulnerable at the same time. Both had problems with their own dependency needs and those of the partner. After successful rehabilitation he had somewhat more energy to try to take her position. To some extent it gave meaning to him to understand her communication as an expression of her helplessness. He was able to stop some of the vicious communication circles. It helped him to put more effort in showing her and arranging activities rather than call out orders. He tried to stop himself from giving negative comments (which made her upset) and joking (which she could not understand). Besides, more day care and a respite stay gave them some physical distance and helped to establish more of a balance, even though it is a rather vulnerable one.

In other couples with a similar proximity-distance contract from the beginning, the regulation have been more easy, due to individual resources and/or the ability of the spouse to get away and/or continue their own activities, but also due to the behaviour of the person with dementia.

$M r . C$ described in details the daily routines in his relationship to his wife. 'I have the mornings on my own, because she is a bit lazy and I like to get up early. I wake her up about 10 o'clock. After I have given her breakfast, she needs a long time in the bathroom and to be dressed. She never goes out of the house on her own, so I don't need to be afraid when I leave her for some hours. Mostly she likes to sit in the kitchen or in front of the TV. Sometimes she looks sad, but she does not talk very much about it. I try to encourage her by taking her out for a walk. When I am busy with some paper work in another room, she comes to the door to see that I am there, but she seldom interrupts me.'

This man structured the daily rounds in a way that gave both of them predictability and structure. He still kept in control and her behaviour did not, so far, provoke this system to a great extent. Like they used to, they shared meals and some activities, but more or less left each other in peace. He felt sympathy for her and was satisfied that he was able to take care of her, do the cooking etc. The daily routines gave structure under the given conditions, things were functioning rather well. He had reduced his expectations of her taking an active share in the household. More important, she fulfilled their proximity-distance contract. When he heared examples of the deviant behaviour of other persons with dementia, he realized that things could have been worse if she had not been 'such a nice person after all'. She was not making too much fuss and he did not have to be available all the time.

\section{I am available for you (Don't drift away from me- we belong together)}

In the example above, doing more of the same, in the sense of making a safe structure seems to have a good effect on the regulation of the relationship as far as the 
spouse reminds himself that the person with dementia is still a person. In the other examples mentioned, doing more of claims, nagging and pushing away have a detrimental effect on the relationship. When the pattern of compulsive caregiving is activated, at first glance this seems to be a perfect fit with the needs of the person with dementia. When the spouse needs more care, what can be better than a caregiver doing more of the same? In this category the greatest threat is the loosening of the bond, a destruction of the 'we'. To confirm the feeling of belongingness these spouses often 'fill in' with what is needed to compensate for the deficits of the spouse. The worst provocation, the threat of being rejected, is often strong in the beginning of the dementia process, before the spouses know what is going on. For example, one wife suspected her husband of having an affair that drew his concentration and concern away from their relationship. When realizing that their spouses cannot be blamed, these spouses are often well-praised caregivers. Their expectations on the partners 'doing' seems to be given up rather easily and compensated by the caregivers, but great efforts are invested in their 'being there' and 'being together'.

These caregivers too may, however, come to a point where it is impossible to do more of the same, due to their own reduced energy, other obligations, or because the behaviour of the spouse represents a hurting breaking out of the 'we-ness'. The feelings of being rejected with corresponding feelings of anger, anxiety and despair may push them a step further in the often long and painful process of letting go.

The intentions of the caregiving spouses to be available to their partners are often strong and not easily changed. The case of Mr. B illustrates this.

$M r . B$ attended to his wife very carefully from the beginning. He was almost overwhelmed by her, and his own feelings of sadness, and he identified with her. He told that for the first time in his life, he could understand why somebody could think about comitting suicide. In the process of dementia, the more help she needed and the less she was able to give back, the more he cared for her. After several years of home care, he almost moved together with her to a nursing home. He visited her for hours two times a day, in addition to keeping their house proper. Although he had gradually reduced his expectations of what they could do together, he still got some non-verbal signals that he mattered for her. 'She is calmer when I stay by her side'. Nothing and nobody could push him away from her. He called it a need of his own to be there. Structuring his day around the visits to her and doing the tasks she used to do at home seemed like a manifestation of not deceiving her and a confirmation of their belonging together, whatever happened. This security was however at the cost of other relationships, activities and experiences. His time table for household tasks and visits at the nursing home gave him no time for relaxation with his grandchildren or time at his adored country house. He had no experience of choice, and resisted all attempts to take a couple of days off on his own. At the same time he regretted that his own life-time was short, without being able to live. He was emotionally close, identified with her feelings, and had no sense of having a life separated from her. He had almost drowned in her dark and hopeless world.

In another case, Mrs. A had a similar history of a close relationship to her husband.

The first signs of 'strange behaviour' was extremely frightening to Mrs. A, but her main theme was how she had tried to hold on to what they had together. Her way of doing this was first to take him with her on trips, concerts and continue to enjoy life as long as possible. She was clever to pick activities and contacts that suited him and arrange for a best possible functioning at home. After he had to move to an institution, she brought as much as possible of their former life to him, including friends, grandchildren, his special food, pictures, music etc. She adapted herself to the situation by developing a new interest in knitting, that is easily combined with sitting together with him. 'It is kind of cosy, and after all, we cannot talk much any longer'. In many ways she tried to fill in and compensate for lost functions and contact. With a few exceptations, she visited him every day, but she had to realize that he was more and more lost for her. '... in a way he is absent, yes, he is'.

She pinpoints that she now, after years of strenuous caregiving, without too much guilt, can drop her daily visit from time to time, if she feels bad, something special is going on in the family, or she just needs some days off. She is more flexible and is better off, compared to $\mathrm{Mr}$. B, also in the sense that she has alternative attachments, someone she cares for and where her feelings, health, and experiences really matters. She lives two lives. 'When I have visited him and walk out, then I shut the door behind me'. The relationship to her husband does not fill her life totally. In a way she was 'helped' by an illness of her own in a very stressful life situation while he still lived at home. She had to leave him for a hospital stay. He had to move to an institution. This represented a turning point. On the one hand she realized that others were in fact capable of taking care of her husband and on the other hand, she understood, by hard practice, that if she refused to put some of her resourses on self-care she was unable to survive and even more unable to represent something positive to him. From her position, making herself available to her husband by 'giving' and making him happy, let some light shine into his life is her way of saying that they belong together. 'When I feel that it does not matter to him any more, I probably will reduce my visits'. With a highly developed sensitivity to his signals and her own needs to 'at least drop in to see him', the time when it does not matter is not a fixed point and it probably will not come as long as he lives. The important matter is that their contact enables her to practice, and not just intellectually understand the following principle: To have something to give, she has to take care of her own health and have other contacts and positive experiences to keep her alive. Her network represented alternative attachment and in addi- 
tion she put great efforts in a self help organization for relatives of Alzheimer sufferers. This may be understood as vicarious attachment. She was an available listener to others and developed contact with others in the 'same world'.

It is easy to forget that extremely resourceful persons like Mrs. A, suffer great losses and are vulnerable to a great many signals of loosening the bond, of not belonging together any longer. The process of letting go is painful. In the process of letting go, the perspectives on the closeness of the relationship and the availability of the caregiver, have to be changed.

Secure attachment makes it easier to accept the changes and still keep in contact, and to tolerate insecurity without panic or freezing the internal working model of attachment.

\section{CONCLUSION}

The behavioural changes associated with the diagnosis of dementia are a threat that easily activates attachment behaviour both by the person with dementia and the family. To understand the strains and the coping of the spouses, we need to understand how dementia triggers their pattern of attachment behaviour.

The process of gradually reducing the expectations, accepting changes in the marriage contracts and in the balance of proximity-distance in the relationship is hard for most spouses. Changing expectations and contracts are extra difficult when the spouse needs his or her partner in fixed roles and positions to feel safe. Dementia means a long process of coping and regulation of the relationship, which includes the ability to let go as well as to maintain important relationships.
We have given some examples of challenges in regulating proximity and distance and expectations in the relationship. These regulations are determined, partly by the attachment pattern of the caregiving spouse, and partly by the reactions of the person with dementia. It is also influenced by situational demands and other relationships and engagements of the caregiver.

In trying to understand and help the caregiver it is useful to try to picture the basic contract in the relationship and how the caregiving spouse tries to balance between the aims of 1) taking care, 2) maintaining a relationship to their dementing spouse, and 3) selfcare.

As regards intervention, this study suggests that the spouses of persons with dementia need more than information on dementia and how to handle different symptoms. They need interventions that are flexible and adapted to changing needs over time and they need empathy and respect, whether they from the perspective of professional caregivers are too involved, seem too detached or do the right or the wrong things. Group interventions may bring in alternative perspectives and be helpful for caregivers in their process of regulating their expectations to their partner - and to themselves as well. In a therapeutic relationship the person's internal working model of attachment may be a more direct focus of attention and probably be revised, giving the caregiver more choices of alternative behaviour in relation to the spouse and alternative attachment and contacts. In a review article, Bourgeois et al. (1996) conclude that multi-component intervention is most likely to succeed, and a diversity of services increases the probability of meeting each caregiver's needs at the appropriate time.

\section{REFERENCES}

Ainsworth MDS, Blehar MC, Waters E, Wall S. Patterns of attachment: A psychological study of the strange situation. Hillsdale, NJ: Erlbaum, 1978.

Antonucci TC. Attachment: A life-span concept. Hum Dev 1976; 19 (3) [Special issue].

Antonucci TC. Attachment in adulthood and aging. In: Sperling MB, Berman WH, eds. Attachment in adults. Clinical and developmental perspectives. New York: Guilford, 1994: 256-272.

Berman WH, Marcus L, Berman ER. Attachment in marital relations. In: Sperling MB, Berman WH, eds. Attachment in adults. Clinical and developmental perspectives. New York: Guilford, 1994: 204-231.

Bourgeois MS, Schulz, Burgio L. Interventions for caregivers of patients with Alzheimer's disease: A review and analysis of content, process, and outcomes. Int J Aging Hum Dev 1996; 43 (1): 35-92.

Bowlby J. Attachment. Vol. I of Attachment and Loss. London: The Hogarth Press, 1969.

Bowlby J. Separation: Anxiety and Anger. Vol. II of Attachment and Loss. London: The Hogarth Press, 1973.

Bowlby J. Loss, Sadness, and Depression. Vol. III of Attachment and Loss. London: The Hogarth Press, 1980.

Bretherton I. Open communication and internal working models: Their role in the development of attachment relationships. In: Thompson RA, ed. Socioemotional Development. Nebraska Symposium of Motivation,1988. Lincoln: University of Nebraska Press, 1990: 57-113.

Cicirelli VG. Attachment theory in old age: Protection of the attached figure. In: Pillemer K, McCartney K, eds. Parent-child relations throughout life. Hillsdale, NJ: Erlbaum, 1991: 25-42. 
Crittenden PM. The effect of early relationship experiences on relationships in adulthood. In: Duck S, ed. Handbook of personal relationships, 2nd edn. Chichester: Wiley, 1997: 91-119.

De Longis A, O'Brien T. An interpersonal framework for stress and coping: An application to the families of Alzheimer's patients. In: Stephens MAP, Growther JH, Hobfoll SE, Tennenbaum DL, eds. Stress and coping in later life families. New York: Hemisphere, 1990: 221-239.

Duijnstee M. Caring for a demented family member at home: objective observation and subjective evaluation of the burden. In: Jones GMMA, Miesen BML, eds. Care-giving in dementia: Research and applications. London: Routledge, 1992: 359-379.

Farran CJ, Keane-Hagerty E, Salloway S, Kupferer S, Wilken CS. Finding meaning: An alternative paradigm for Alzheimer's disease family caregivers. Gerontologist 1991; 31: 483-489.

George LK, Gwyther LP. Caregiver well-being: A multidimensional examination of family caregivers of demented adults. Gerontologist 1986; 26: 253-259.

Grafström M. The experience of burden in the care of elderly persons with dementia. Doctoral dissertation, Karolinska Institute, Stockholm Gerontology Research Center, and Umeå University, Sweden, 1994.

Gwyther LP. Letting go: Separation-individuation in a wife of an Alzheimer's patient. Gerontologist 1990; 30: 698-702.

Ingebretsen R, Solem PE. Caring for a dementing spouse. Attachment, loss and relationship-focused coping. In: Miesen BML, Jones GMMA, eds. Care-giving in dementia, Vol II. London: Routledge, 1997: 191-209.

Kitwood T. The experience of dementia. Aging Mental Health 1997; 1 (1): 13-22.

Lazarus RS. Coping with aging: Individuality as a key to understanding. In: Nordhus IH, VandenBos GR, Berg S, Fromholt P, eds. Clinical geropsychology. Washington, D. C.: American Psychological Association, 1998: 109-127.

Lazarus RS, Folkman S. Stress, appraisal and coping. New York: Springer, 1984.

Lévesque L, Cossette S, Lachance L. Predictors of the psychological well-being of primary caregivers living with a demented relative: A 1-year follow-up study. J Appl Gerontol 1998; 17 (2): 240-258.

Main M, Kaplan K, Cassidy J. Security in infancy, childhood and adulthood: A move to the level of representation. In: Bretherton I, Waters E, eds. Growing points of attachment theory and research, Monographs of the Society for Research in Child Development 1985; 50 (1-2, Serial No. 209): 66-104.

Main M, Solomon J. Procedures for identifying infants as disorganized/disoriented during the Ainsworth Strange Situation. In: Greenberg M, Cicchetti D, Cummings M, eds. Attachment in the preschool years: Theory, research and intervention. Chicago: University of Chicago Press, 1986: 121-160.

Mayseless O. Attachment patterns and their outcomes. Hum Dev 1996; 39: 206-223.

Miesen BML. Attachment theory and dementia. In: Jones GMMA, Miesen BML, eds. Care-giving in dementia: Research and applications. London: Routledge, 1992: 38-56.

Morris RG, Morris LW. Psychosocial aspects of caring for people with dementia: Conceptual and methodological issues. In: Burns A, ed. Aging and dementia: A methodological approach. London: Edward Arnold, 1993: 251-274.

Motenko AK. The frustrations, gratifications and well-being of dementia caregivers. Gerontologist 1989; 29: 166172 .

Nordhus IH. Parter i samspill - pårørende i demensprosessen. In: Solem PE, Ingebretsen R, Lyng K, Nygård AaM, ed. Psykologiske perspektiver på aldersdemens. Oslo: Universitetsforlaget, 1994: 170-181.

Rose JM, DelMaestro SG. Separation-individuation conflict as a model for understanding distressed caregivers: Psychodynamic and cognitive case studies. Gerontologist 1990; 30: 693-697.

Sperling MB, Berman WH, eds. Attachment in adults. Clinical and developmental perspectives. New York: Guilford, 1994.

Zarit SH, Todd PA, Zarit J. Subjective burdens of husbands and wives as caregivers: A longitudinal study. Gerontologist 1986; 26: 260-266. 